\title{
TRANSPLANTE HEPÁTICO ORTOTÓPICO EXPERIMENTAL EM SUÍNOS: ASPECTOS TÉCNICOS (II)
}

\author{
Operative technique of experimental orthotopic liver transplantation in swine
}

\begin{abstract}
Orlando Jorge Martins Torres ${ }^{1}$, Patrícia Brandão Pantoja ${ }^{2}$, Érica Sampaio Barbosa ${ }^{2}$, Raquel Aranha Viegas ${ }^{2}$, Elisabeth Teixeira Noguera Servin ${ }^{3,4}$, Poliana Cristina Oliveira Moreira ${ }^{2}$, Edson Dener Zandonadi Ferreira ${ }^{2}$, Noelia Dias Carneiro Barros ${ }^{2}$, Cristiany de Almeida Barros ${ }^{2}$, Santiago Cirilo Noguera Servin ${ }^{3}$, Josiel Paiva Vieira ${ }^{3}$, Natalino Salgado Filho ${ }^{3}$, Waston Gonçalves Ribeiro ${ }^{3,4}$
\end{abstract}

\begin{abstract}
RESUMO
Racional: O transplante hepático ortotópico é um procedimento tecnicamente complexo que requer atenção a detalhes para alcançar resultados satisfatórios. Antes do procedimento em humanos, o treinamento das equipes pode ser realizado em modelos animais com a finalidade de adquirir a habilidade necessária para o transplante. O porco apresenta considerável similaridade anatômica com humanos, bem como comparável sensibilidade fisiológica e hemodinâmica, e tem sido usado como modelo para pesquisas experimentais. Objetivos: Pretendemos neste estudo apresentar os detalhes da técnica utilizada para o transplante hepático ortotópico experimental em suínos. Método: Os animais foram mantidos em jejum por 24 horas antes da cirurgia e toda operação foi desenvolvida sob anestesia geral. Foram utilizadas porcas da raça Landrace, distribuídas em grupos de doador e receptor, pesando entre 32 e $38 \mathrm{Kg}$. Resultados: O procedimento cirúrgico foi dividido em cirurgia do doador, back-table, hepatectomia do receptor e implante do enxerto. O by-pass passivo veno-venoso em Y da veia ilíaca esquerda e veia esplênica em direção à veia jugular interna esquerda, foi realizado para evitar as repercussões hemodinâmicas da fase anepática. A seqüência da anastomose vascular foi veia cava supra-hepática, veia porta, veia cava infra-hepática e artéria hepática. Conclusões: o protocolo de transplante hepático experimental em suínos é capaz de aperfeiçoar a técnica cirúrgica, bem como estimular pesquisas em transplante hepático.
\end{abstract}

Descritores:transplante hepático, suínos, cirurgia experimental, técnica cirúrgica.

Trabalho realizado no Programa de Transplante Hepático Experimental do Hospital Universitário da Universidade Federal do Maranhão - UFMA. Patrocinado pelo CNPq - Conselho Nacional de Desenvolvimento Científico e Tecnológico.

1. Professor Livre-Docente do Departamento de Cirurgia da Universidade Federal do Maranhão - UFMA

2. Estudantes de Medicina - UFMA, Bolsistas do PIBIC-CNPq-UFMA

3. Médicos do Programa de Transplante Hepático Experimental - HUPD-UFMA

4. Mestrando em Ciências da Saúde - UFMA

Endereço para correspondência: Dr. Orlando Torres - Rua dos Bicudos 14/600 Ed. Aspen - Renascença II - CEP: 65075-090 - São Luís - MA - Brasil - Fone (98) 3227-4009 Fax (98) 3227-4073 - E-mail: o.torres@uol.com.br

Recebido em: 20/06/05 Aceito em: 05/07/05

\section{INTRODUÇÃO}

Desde o primeiro transplante hepático clínico realizado em 1963 nos Estados Unidos e em 1968, no Brasil, esta modalidade terapêutica tem sido utilizada de forma eficiente para uma variedade de doenças hepáticas agudas e crônicas, em estágio terminal, para as quais nenhuma outra terapia satisfatória está disponível. ${ }^{1,2,3}$ Os avanços na imunossupressão, técnica cirúrgica, anestesia e controle pósoperatório têm determinado um aumento nas taxas de sobrevida pós-transplante. Atualmente, os pacientes submetidos ao transplante hepático podem alcançar uma sobrevida de $93 \%$ até o terceiro mês, $88 \%$ no primeiro ano e $74 \%$ em cinco anos pós-transplante. ${ }^{4,5,6} \mathrm{O}$ interesse atual no transplante hepático, como forma tratamento destes pacientes com doença hepática terminal irreversível, tem estimulado a implantação de programas de transplantes clínicos. Em função da complexidade técnica envolvida no transplante hepático, o treinamento das equipes anestésico-cirúrgicas através de cirurgias experimentais em animais tem sido considerado como passo fundamental antes de sua aplicação clínica. ${ }^{7,9,9}, 10$ Os objetivos de um programa de transplante hepático experimental têm sido o de treinar uma equipe especializada nos aspectos técnicos que este procedimento tanto necessita, bem como a realização de pesquisas experimentais ligadas ao transplante. ${ }^{9,10,11}$ Pretendemos neste estudo apresentar os detalhes da técnica operatória utilizada 
310 Orlando Jorge Martins Torres, Patrícia Brandão Pantoja, Érica Sampaio Barbosa, Raquel Aranha Viegas, Elisabeth Teixeira Noguera Servin, Poliana Cristina Oliveira Moreira, Edson Dener Zandonadi Ferreira, Noelia Dias Carneiro Barros, Cristiany de Almeida Barros, Santiago Cirilo Noguera Servin, Josiel Paiva Vieira, Natalino Salgado Filho, Waston Gonçalves Ribeiro

para o transplante hepático ortotópico experimental em suínos na Universidade Federal do Maranhão.

\section{MATERIAL E MÉTODO}

Este estudo foi aprovado pela comissão de ética e pesquisa experimental em animais da Universidade Estadual do Maranhão (UEMA). Os transplantes foram realizados no Laboratório de Pesquisas em Cirurgia Experimental do Hospital Universitário da Universidade Federal do Maranhão (UFMA).

\section{ANESTESIA E MONITORIZAÇÃO}

Foram utilizadas porcas, da raça Landrace, distribuídas em grupos de doador e receptor, pesando entre 32 e $38 \mathrm{Kg}$. Antes da cirurgia, os animais foram mantidos em jejum por 24 horas. Toda operação foi desenvolvida sob anestesia geral. A indução anestésica foi realizada por sedação com diazepam $(0,3 \mathrm{mg} / \mathrm{kg}) \mathrm{e}$ fentanil $(5-7 \mu \mathrm{g} / \mathrm{kg})$, por acesso venoso periférico até relaxamento do animal. Este era, em seguida, transferido para a sala de cirurgia, fixado à mesa cirúrgica e submetido à ventilação com oxigênio a $100 \%$ e isoflurano, sob máscara facial até o desaparecimento do reflexo corneano. Procedeu-se a intubação orotraqueal com laringoscópio com lâmina reta número 5 e tubo orotraqueal ${ }^{6,5-7,5}$, com balonete que era insuflado até ausência de vazamento durante a ventilação manual. Iniciou-se a ventilação mecânica controlada com pressão positiva e oxigênio a 100\% . A manutenção anestésica foi realizada com isoflurano (1,5 CAM), fentanil (bolus de 1-2 $\mu \mathrm{g} / \mathrm{kg}$ se taquicardia ou hipertensão) e pancurônio (bolus de 0,1 $\mathrm{mg} / \mathrm{kg}$ quando sinais de ventilação espontânea). A monitoração foi realizada com cardioscópio com cinco derivações, oximetria e cardioscopia

No animal receptor, realizou-se dissecção da veia jugular externa direita, instalou-se o sistema para monitoração da pressão venosa central (PVC) e da artéria carótida comum direita, para medida contínua da pressão arterial média (PAM). O monitoramento da diurese foi realizado após a realização da cistostomia e instalação do sistema coletor no animal receptor. No início do by-pass venovenoso, administrou-se heparina (100 UI/ $/ \mathrm{kg})$ e hidrocortisona $(2,5$ $\mathrm{mg} / \mathrm{kg})$. No caso de hipotensão, fizemos uso de etilefrina (1mg/ $\mathrm{kg}$ ), noradrenalina em bomba de infusão (inicialmente $10 \mathrm{~mL} / \mathrm{h}$ ) imediatamente antes da reperfusão. Atropina $(1,0 \mathrm{mg})$ e adrenalina (1$3 \mathrm{mg}$ ) foram utilizadas sempre que necessário. A reposição volêmica foi feita com cristalóides, com reposição de $2 \mathrm{~mL} / \mathrm{Kg} / \mathrm{h}$, no início da anestesia, e manutenção com $20 \mathrm{~mL} / \mathrm{Kg} / \mathrm{h}$. Durante a cirurgia do doador o sangue venoso foi coletado em bolsas contendo citrato para transfusão do receptor. Utilizou-se controle gasométrico no animal receptor onde a primeira gasometria era colhida no momento da canulação da artéria, a segunda quando da retirada do fígado (início da fase anepática) e a terceira após reperfusão do enxerto.

\section{OPERAÇÃO DO DOADOR}

Após anti-sepsia do animal com clorexidina, os campos operatórios foram colocados desde a pelve até o ângulo da mandíbula. Realizouse uma incisão longitudinal de 3 a $5 \mathrm{~cm}$ em região cervical, logo abaixo do ângulo da mandíbula, seguindo a borda medial do músculo esternomastóide, para acesso venoso pela veia jugular externa à esquerda, com utilização de cateter de polietileno número 12, para infusão de líquidos e remoção de sangue total para hemotransfusão no receptor. A exsangüinação do animal doador foi realizada simultaneamente ao procedimento.

Uma incisão mediana foi realizada usando eletrocautério, estendendo do esterno ao púbis. A incisão ultrapassou a linha Alba e o peritônio. A dissecção começou com o preparo da aorta abdominal distal, imediatamente acima da bifurcação das artérias ilíacas, após incisão do peritônio posterior e um segmento de aproximadamente 5 centímetros foi preparado e cateterizado com cateter de polietileno n.14. Proximalmente, a aorta era preparada no nível do diafragma para pinçamento. Em seguida a veia esplênica foi dissecada e cateterizada com cateter de polietileno n.12, introduzido até a veia porta, guiado por palpação. A aorta no nível do diafragma foi então pinçada e iniciou-se o resfriamento central com um litro de solução de Ringer Lactato a $4^{\circ} \mathrm{C}$ pela aorta e um litro de solução de preservação (Euro-Collins ${ }^{\circledR}$ ) a $4^{\circ} \mathrm{C}$ pela veia esplênica. Neste momento foi colocado gelo picado na cavidade abdominal. A vesícula biliar foi aberta e suavemente lavada com solução de Ringer Lactato a $4^{\circ} \mathrm{C}$ para evitar autólise. A veia cava supra-diafragmática foi seccionada imediatamente após a coleta do sangue e antes da infusão da solução de preservação, 5 a 8 centímetros acima do diafragma para permitir tecido venoso suficiente no enxerto para confecção da anastomose, durante o transplante no receptor.

$\mathrm{O}$ preparo do pedículo hepático começou com o isolamento e secção do ducto biliar comum, o mais próximo do duodeno. A dissecção do ligamento hepatoduodenal continuou com o preparo da veia porta abaixo de sua junção com a veia esplênica após ligadura da veia gástrica esquerda. A veia mesentérica superior foi então ligada e dividida. A artéria hepática comum dissecada o mais próximo possível do estômago. Todos os ramos sucessivos da artéria celíaca, outras que não a artéria hepática comum, foram ligadas com fio de Vicryl ${ }^{\circledR}, 2.0$ e divididos. O pâncreas foi mobilizado e dividido, após secção da veia mesentérica superior. A artéria mesentérica superior liberada para baixo em direção à aorta a uma distância de cinco centímetros, foi ligada e dividida. A aorta foi seccionada acima e abaixo do tronco celíaco e o patch de Carrel foi confeccionado. O fígado foi mobilizado primeiro para a esquerda para permitir cuidadosa divisão do peritônio junto da veia cava retro-hepática. Esta dissecção segue em sentido distal para secção da veia cava no nível da veia renal esquerda permitindo extensão suficiente para anastomose. A veia cava intratorácica, seccionada previamente, foi removida junto com $10 \mathrm{~mm}$ de tecido diafragmático deixado aderente ao vaso. $O$ fígado podia agora ser removido, após secção da veia cava infra-hepática e liberação diafragmática.

\section{CIRURGIA DE MESA (BACK-TABLE)}

O fígado foi colocado em uma bolsa plástica estéril, dentro de uma bacia de aço inoxidável contendo gelo picado. Neste momento, a perfusão com solução de Euro-Collins ${ }^{\circledR}$ a $4^{\circ} \mathrm{C}$ se iniciou através da veia porta e artéria celíaca para conservação. Para o preparo do fígado realizamos duas suturas em chuleio semicirculares de fio de Vicryl $\mathbb{\circledR}$, 3.0 ao redor do manguito diafragmático da veia cava supra-hepática para obliterar os vasos confluentes, especialmente as veias frênicas. Todas as tributárias dos grandes vasos foram ligadas e a permeabilidade controlada. Esta técnica preserva a veia cava retro-hepática, a veia porta e a vesícula biliar. Imediatamente antes do implante do enxerto, dois litros de solução de Ringer Lactato resfriado a $4^{\circ} \mathrm{C}$ foram utilizados para limpeza do enxerto através da veia porta. Este procedimento retira a solução de preservação (Euro-Collins $\left.{ }^{\circledR}\right)$, rica em potássio, previamente usada na perfusão bem como possíveis bolhas de ar. 


\section{HEPATECTOMIA DO RECEPTOR}

Durante todo o procedimento, o controle da hemostasia permaneceu como a principal preocupação, uma vez que os porcos são muito sensíveis a perdas sanguíneas.

Após anestesia geral do animal receptor, que seguiu o mesmo protocolo anestésico do animal doador, foram obtidos três acessos venosos cervicais. A artéria carótida comum direita foi cateterizada (cateter de polietileno n. 10) para mensuração invasiva da pressão arterial média, a veia jugular interna esquerda foi cateterizada (cateter de polietileno n. 12) para administração de líquidos e para o by-pass veno-venoso durante a fase anepática e a veia jugular externa direita foi cateterizada (cateter de polietileno n. 12) para administração de líquidos, medicamentos, sangue e monitoramento da PVC.

Uma incisão mediana foi realizada usando o eletrocautério, estendendo do esterno ao púbis. Após abertura do peritônio, realizou-se uma cistostomia com cateter vesical tipo Foley (n. 12) para monitoração da diurese. A dissecção começou com a cateterização da veia ilíaca comum esquerda (cateter de polietileno n. 14) e da veia esplênica (cateter de polietileno n. 12) as quais foram utilizadas na confecção do by-pass veno-venoso durante a fase anepática. Em seguida, iniciou-se a dissecção do ligamento hepatoduodenal, que foi aberto, o ducto hepático comum dividido, próximo ao fígado, após ligadura distal. A artéria hepática comum foi identificada na junção da veia porta e veia esplênica, liberada de seus ramos menores e dissecada do tecido conjuntivo adjacente. A mais adequada porção para uma anastomose termino-terminal adicional foi escolhida e a artéria ligada e dividida acima deste local. A veia porta foi dissecada na junção com a veia esplênica, após ligadura de suas tributárias e principalmente a veia gástrica esquerda. Em seguida, foi procedida a divisão do ligamento falciforme e dos ligamentos triangulares, direito e esquerdo bem como liberação da veia cava infra-hepática. A veia porta e a veia cava inferior infra-hepática foram pinçadas. Neste momento o by-pass passivo veno-venoso em Y da veia ilíaca esquerda e veia esplênica em direção à veia jugular interna esquerda estava completamente funcionante (Figura). Previamente havia sido administrado 100 UI de heparina por kg de peso do animal, endovenoso.

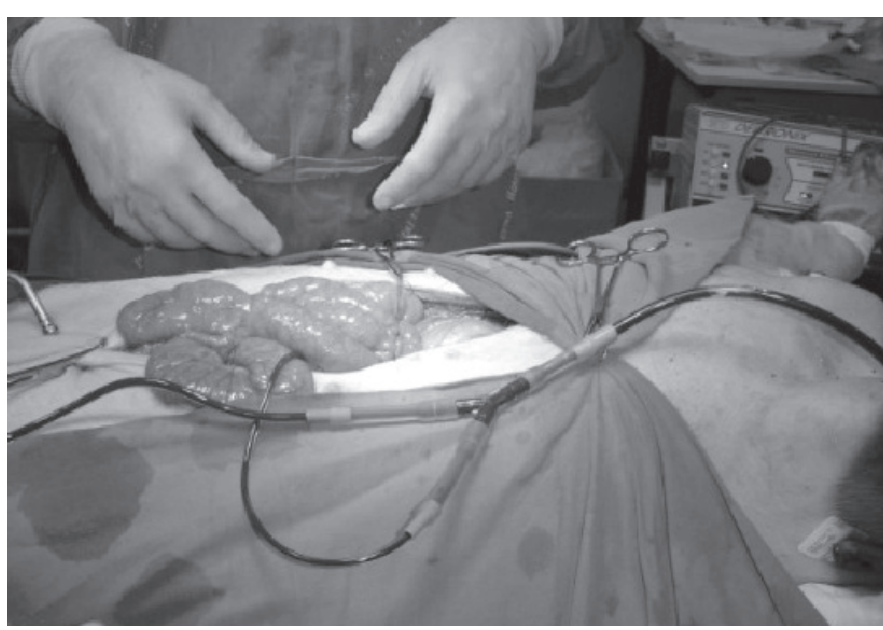

Figura - Funcionamento do Sistema de By-pass veno-venoso em Y
Realizou-se a liberação da veia cava supra-hepática das aderências posteriores para permitir a passagem das pinças. As veias diafragmáticas foram ligadas com pontos transfixantes de fio de Vicryl ${ }^{\circledR}, 2.0$, para evitar vazamentos durante a fase anepática e após a anastomose vascular. O fígado do receptor já podia ser removido e duas pinças de Satinsky foram colocadas na veia cava supra-hepática. A primeira delas permitia a oclusão da veia e incluía uma considerável porção do diafragma. Com uma tração suave colocou-se a segunda no local, o mais proximal possível. Realizouse a secção da veia cava supra-hepática o mais próximo possível do fígado, com a secção passando através das veias hepáticas. Em seguida, foi realizada a secção das veias porta e cava infra-hepática acima das pinças de Satinsky. Concluiu-se então, a hepatectomia total do receptor.

\section{IMPLANTE DO ENXERTO}

O fígado, previamente perfundido com dois litros de solução de Ringer Lactato através da veia porta, foi posicionado no espaço subdiafragmático direito e a anastomose da veia cava suprahepática foi realizada após remoção da pinça caudal de Satinsky. A anastomose foi realizada com sutura contínua posterior com fio de Polipropileno 4.0, com duas agulhas, da esquerda para a direita, intra-luminal. A sutura anterior iniciou-se também à esquerda com irrigação intra-luminal com solução fisiológica a $0,9 \%$, para minimizar o risco de embolia gasosa. Em seguida, a anastomose da veia porta foi realizada com sutura contínua intra-luminal posterior com Polipropileno 5.0, de duas agulhas. A sutura anterior iniciouse também à esquerda com irrigação intra-luminal com solução fisiológica a $0,9 \%$. Os nós cirúrgicos com fator de crescimento, no ângulo direito da veia porta, terminaram o procedimento. Desta forma a veia porta retornou ao diâmetro normal após a reperfusão. Imediatamente as pinças da veia porta foram liberadas e ao mesmo tempo o fígado foi aquecido com solução fisiológica a $0,9 \%$, morna. A liberação da pinça da veia cava supra-hepática foi realizada lentamente. Com a reperfusão do enxerto, foi determinado o fim da fase anepática. Realizou-se, a seguir, a inspeção das anastomoses vasculares, garantindo a integridade das mesmas e a ausência de vazamentos, que seriam corrigidos caso estivessem presentes.

A anastomose da veia cava infra-hepática foi realizada com suturas contínuas de Polipropileno 5.0, com duas agulhas, iniciadas por uma sutura intra-luminal posterior, e subseqüente liberação do seu pinçamento. Nesta etapa do procedimento retirou-se o sistema de by-pass veno-venoso com subseqüente ligadura desses vasos. A anastomose término-terminal da artéria hepática foi então realizada com pontos separados de Polipropileno 7.0, com o uso de lupas de 2,5 X de aumento.

$\mathrm{O}$ próximo passo consistiu na anastomose bilio-digestiva do tipo colecisto-duodenostomia com sutura contínua com fio de Vicryl ${ }^{\circledR}$, 4.0. Avaliou-se a hemostasia e a integridade das anastomoses. Finalmente a parede abdominal foi suturada em plano único com fio de algodão n. 0 e a pele foi aproximada com fio de algodão 2.0. Não foi utilizada drenagem.

\section{DISCUSSÃO}

O laboratório de cirurgia experimental iniciou o protocolo de transplante hepático em suínos recentemente. Este procedimento tem como propósito, o treinamento da equipe para transplante, bem como para a realização de estudos experimentais utilizando suínos. O porco tem considerável similaridade anatômica com o homem e 
312 Orlando Jorge Martins Torres, Patrícia Brandão Pantoja, Érica Sampaio Barbosa, Raquel Aranha Viegas, Elisabeth Teixeira Noguera Servin, Poliana Cristina Oliveira Moreira, Edson Dener Zandonadi Ferreira, Noelia Dias Carneiro Barros, Cristiany de Almeida Barros, Santiago Cirilo Noguera Servin, Josiel Paiva Vieira, Natalino Salgado Filho

Waston Gonçalves Ribeiro

comparável sensibilidade fisiológica e hemodinâmica. Ao mesmo tempo é menos sujeito a restrição ética que o cão. ${ }^{8,9,12}$

O manuseio anestésico, bem como a técnica cirúrgica, com algumas alterações é, não somente similar àquelas aplicadas ao humano como também proporcionam um modelo experimental seguro e fácil de ser reproduzido. ${ }^{10,11,13,14,15,16,17,18}$ A principal diferença técnica tem sido a dificuldade de preservação da veia cava do receptor (técnica de Piggyback). Estudo realizado previamente, utilizando a técnica de Piggyback em suínos não foi reproduzido no presente experimento ${ }^{19}$.

A utilização de dois animais por transplante (doador e receptor) proporcionou um maior aprendizado técnico que os outros modelos que usam apenas um animal ${ }^{9,10,20}$. O tempo operatório total no presente estudo foi de aproximadamente cinco horas. $\mathrm{O}$ modelo de captação seguiu os propósitos da captação de múltiplos órgãos, entretanto, com a perfusão sendo realizada através da veia esplênica. ${ }^{916}$ Com a utilização de monitorização multiparamétrica e avaliação gasométrica pudemos realizar estudos das repercussões do transplante hepático em diferentes fases do procedimento, como nas fases anepática e de reperfusão do enxerto. ${ }^{21,22,23}$

O uso do by-pass passivo com o animal heparinizado, durante a fase anepática, previne as graves alterações hemodinâmicas observadas no pinçamento simultâneo do pedículo hepático e da veia cava infrahepática. Um outro procedimento utilizado é o pinçamento da aorta supracelíaca durante a fase anepática. Esta técnica foi aplicada em uma das fases da evolução deste programa ${ }^{14,24}$. Apesar de alguns trabalhos demonstrarem que a fase anepática sem by-pass venovenoso pode ser facilmente tolerada por um período de 30 minutos, tempo suficiente para realizar as duas anastomoses venosas antes da reperfusão, preferimos utilizar o by-pass veno-venoso. ${ }^{14,19}$

\section{CONCLUSÃO}

Concluímos que o protocolo de transplante hepático experimental em suínos é capaz de aperfeiçoar a técnica cirúrgica bem como estimular a realização de pesquisas em transplante hepático.

\section{ABSTRACT}

Background: Experimental orthotopic liver transplantation is a technically complex procedure requiring a meticulous attention to many details, in order to attain optimal results. Prior to the human liver transplantation, exhaustive training is performed in animal models, in order to attain the demanded expertise in such procedure. Pigs have considerable anatomic similarities to man, as well as comparable physiological and hemodynamic sensitivity, and they have been used as model for experimental researches. Objective: The aim of the present study was to describe the technique of experimental orthotopic liver transplantation in pigs. Methods: Prior to the surgery, animals were kept in a 24 hours fasting, and all operations were carried out under general anesthesia. Female Landrace pigs were divided in two groups: pairs of donor and recipient were used with weights between 32 and $38 \mathrm{Kg}$. Results: Animals undergone orthotopic liver transplantation and they received whole liver grafts. The surgical procedure was divided in four parts: harvested, back-table, hepatectomy of the recipient and re-implantation. A passive veno-venous by-pass from the left iliac and splenic vein to the left internal jugular vein was performed, in order to avoid severe hemodynamic disturbances during the anhepatic phase. The sequence of the vascular anastomosis was suprahepatic vena cava, portal vein, infrahepatic vena cava, and hepatic artery. Conclusion: The training protocol of experimental liver transplantation in pigs improves the technique and provides an excellent experimental model to the research.

Keywords: Liver transplantation, pig model, experimental surgery, surgical technique.

\section{REFERÊNCIAS}

1. Starzl T, Marchioro TL, Von Kaulla KN, Hermann G, Brittain RS, Waddel WR Homotransplantation of the liver in humans. Surg Gynecol Obstet 1963; 117:659-676.

2. Bacchella T, Machado MCC. The first clinical liver transplantation of Brazil revisited Transplant Proc 2004; 36: 929-930.

3. Rela M, Agarwal A- Liver transplantation. J Gastroenterol Hepatol 2002; 17:294-297.

4. Bambha K, Kim W R. Liver transplantation is effective, but is it cost-effective? Liver transplant 2003; 9:1308-1311.

5. Juan H, Innocenti FA- Liver transplantation in Latin America: current satus Transplant Proc 2004 36;1667-1668.

6. Keeffe EB- Liver transplantation: current status and novel approaches to liver replacement. Gastroenterology 2001; 120:749-762.

7. Busuttil RW, Tanaka K. The utility of marginal donors in liver transplantation. Live transplant 2003; 9; 651-663.

8. Hojo, N, Ishibashi T, Yasuda T, Sakuma Y, Fujiwara T, Kawarasaki H, et al- Porcine model for surgical training of living related liver transplantation, Transplant Proc 2003; 35: 82-84

9. Steinig, D Mentha G, Lecoultre C, Pittet JF, Jeanjacquot A, Huber O, et al-
Experimental porcine orthotopic liver transplantation: a training protocol for transplantation in humans. Helv Chir Acta 1990; 57:177-186.

10. Woodle ES, Hunter GC, Eisele P, Talken L, Ward RE. Orthotopic porcine liver transplantation: operative technique. J Surg Res 1985; $39: 483-488$.

11. Laino GM, Anastasi A, Fabbri LP, Gandini E, Valanzano R, Fontanari P, et alTrapianto di fegato sperimentale nel maiale. Minerva Chir 1996; 51: 765-772.

12. Filipponi F, Falcini F, Benassai C, Martini E. Orthotopic liver transplant in pigs: several variations of the surgical technic. G Chir 1989;10:374-8

13. De Lange JJ, Hoitsma HF, Meijer S. Anaesthetic management in experimental orthotopic liver transplantation in the pig. Eur Surg Res 1984; 16:360-365.

14. Eisele PH, Woodle ES, Hunter GC, Talken L, Ward RE. Anesthetic, preoperative and postoperative considerations for liver transplantation in swine. Lab Anim Sci 1986; 36: 402-405.

15. Falcini F, Martini E, Marsili M, Benassai C, Fabbri LP, Tanini R, et al- Veno-venous bypass in experimental liver transplantation: portal-jugular versus caval-portaljugular. G Chir 1990;11:206-210.

16. Martinez-Ibanez V, Margarit-Creixell O, Boix-Ochoa A. A new experimental model of liver transplant in pigs. An Esp Pediatr 1987;26:107-110. 
17. Oike F, Uryuhara K, Otsuda M, Dehoux JP, Otte JB, Lerut J, et al- Simplified technique of orthotopic liver transplantation in pigs. Transplantation 2001; 71: 328331.

18. Tanaka K, Nishimura A, Ogata S, Yoshimine M, Ikoma A, Taira A- A simple method for liver transplantation in pigs. Transplantation 1994; 58: 1139-1142.

19. Miao X, Zhao H, Qi H. The model of piggyback orthotopic liver transplantation in pigs.HunanYi Ke Da XueXue Bao 1999; 24:77-79.

20. Gruttadauria,S Marino G, Catalano F, Sgroi AV, Di Mauro GL, Basile F. Porcine orthotopic liver autotransplantation: facilitated technique. J Invest Surg 2001; 14: 79-82.

21. Oldhafer KJ, Schuttler W, Hauss J, Spiegel HU, Pichlmayr R- Analysis of hepatic hemodynamics after orthotopic liver transplantation: an experimental study in pigs. Transplant Proc 1993; 25: 2599-2599.

22. Taniguchi H, Takada K, Fukunaga K, Yuzawa M, Otsuka K, Todoroki F. Establishment of a swine model for auxiliary partial orthotopic liver transplantation. Transplant Proc 1998; 30: 3232-3236.

23. Van AS AB, Lotz Z, Tyler M, Adams S, Ryffel B, Kahn D- Histological assessment after different methods of reperfusion following liver transplantation. S Afr J Surg 2002; 40 :95-98.

24. Lopez-Santamaria M, Migliazza L, Gamez M, Murcia J, Paz Cruz JA, Munoz J, et al-Supraceliac aortic clamping during the anhepatic phase of experimental orthotopic liver transplantation.. J Pediatr Surg 1999; 34:1374-1377. 